\title{
Prensa gratuita para inmigrantes en el País Vasco: una lucha por la supervivencia
}

Free press for immigrants in the Basque Country: a struggle for survival

María Teresa Santos Díez. Universidad del País Vasco

Jesús Ángel Pérez Dasilva. Universidad del País Vasco

Recibido: 16-XII-2010 - Aceptado: 6-IX-2011

Resumen:

Este artículo se centra en el estudio de los periódicos gratuitos destinados a la población inmigrante en el País Vasco. Se trata de unos medios que surgen impulsados en unos casos por los propios inmigrantes, mientras que en otras ocasiones son consecuencia de políticas de expansión de grupos de comunicación que intentan introducirse en este nuevo sector. En el estudio se abordan las estrategias de mercado que adoptan los editores con el fin de superar la crisis, además se contemplan otros aspectos como los contenidos y la publicidad.

Palabras clave:

Periódicos para inmigrantes, Periódicos gratuitos, Publicidad, Latinos.

Abstract:

This article focuses on the study of free newspapers aimed at the immigrant population in the Basque Country. This is a type of media that arises in some cases driven by immigrants, while at other times they are the result of expansionary policies of media groups that try to enter into this new sector. The article addresses the marketing strategies that publishers take to overcome the crisis, and it also covers other aspects such as content and advertising.

Keywords:

Newspapers for immigrants, Free newspapers, Advertising, Latin media 


\section{Introducción}

En la Comunidad Autónoma Vasca los inmigrantes de origen latino cuentan con algunos periódicos gratuitos que contribuyen a fomentar la integración y la multiculturalidad. Es un sector de población que no se ve reflejado en la prensa tradicional generalista, ya que esta solo habla de ellos cuando son protagonistas de sucesos, mafias o pateras, aportando una visión negativa del fenómeno migratorio (Gonzalez, 2009). Además, este colectivo también percibe en los medios generalistas una ausencia de noticias de sus países de origen con los que mantienen vínculos familiares a pesar de la distancia. Esta carencia periodística lleva a los propios inmigrantes a crear y promover unos medios que reflejen su realidad y respondan a sus necesidades informativas. Marcan la diferencia especializándose en contenidos elaborados desde una óptica diferente a los medios convencionales.

En el País Vasco existe una importante oferta de medios impresos plenamente consolidados tanto gratuitos como de pago. No obstante, en tiempos de crisis son las publicaciones pequeñas de ámbito local, como las impulsadas por estos colectivos, las que sufren con mayor crudeza, dada la fragilidad de los sectores publicitarios que acuden a estos soportes para incluir sus productos. Tal es el caso de El Boga (2005), que surge en Vitoria, Nuevo Euskadi (2007) en Bilbao, y el periódico Toumai edición Norte (2008) de Ediciones Toumai. La recesión económica afecta de manera muy negativa a este sector, que ve cómo disminuyen sus ingresos por venta de publicidad, que es su única fuente de financiación, algo que les obliga a iniciar un proceso de ajustes con el fin de poder continuar en el mercado.

\section{Metodología}

El artículo es el resultado de una investigación más amplia desarrollada en la CAPV. Se centra en el análisis de los cambios experimentados por los periódicos gratuitos especializados destinados a la población inmigrante latina en la Comunidad Autónoma Vasca. El periodo de tiempo elegido comprende desde enero de 2009 a octubre de 2010. Fechas que coinciden con momentos álgidos de la crisis económica y que obliga a estos medios a buscar soluciones para afrontarla. Con el fin de lograr los objetivos propuestos se procede a trabajar con el universo total de Nuevo Euskadi (6 ejemplares) y El Boga (8 ejemplares). A su vez, de la revista con periodicidad mensual Toumai se opta por elegir 9 ejemplares. En total se contabilizan 23 ejemplares, que se estudian en su totalidad para realizar el análisis de los contenidos y la publicidad. También se abordan otros aspectos básicos considerados de interés como son el origen, promotores y objetivos de las publicaciones mencionadas.

Asimismo se consultaron informes de organismos como el Instituto Nacional de Estadística (INE), el Observatorio Vasco de Inmigración (Ikuspegi) y el Observatorio de la Diversidad (Mugak). Además se ha recurrido a fuentes tales como bases de datos, artículos científicos en revistas de comunicación, páginas web, PGD y CIS. Finalmente, fue necesario recurrir a entrevistas con responsables de las publicaciones mencionadas con el fin de recabar datos de interés para la investigación. 


\section{El público inmigrante}

En la CAPV la inmigración es un fenómeno relativamente reciente. En el año 2005 esta población alcanzaba solo el 1,9\%, frente al 8\% en España (elpais.com 7/7/2005). Esta baja tasa puede deberse en parte a la estructura económica existente en la Autonomía, donde sectores como la hostelería y la agricultura no tienen el mismo peso que en otras zonas del Estado. Y es en estos gremios sobre todo donde trabaja esta población. Estas circunstancias, quizá sean determinantes para que la inmigración sea más escasa que, por ejemplo, en Madrid, Levante o Murcia. Según el Observatorio Vasco de la Inmigración (Ikuspegi) el porcentaje de población entre los años 2005 y 2008 se incrementa en un 60\%, es decir se ha pasado de 72.894 a 116.650 inmigrantes. Según los datos provisionales del Padrón Municipal ofrecidos en abril de 2010, el 1 de enero había en España 5.708.940 de inmigrantes, que constituyen el 12,2 \% del total de la población. A su vez en la CAPV la cifra total alcanzaba los 139.229 inmigrantes, que constituyen el 6,4 \% de la población según datos INE. (INE: junio: 2010).

En cuanto a su distribución geográfica, según datos del INE publicados en abril 2010, Vizcaya es la provincia que concentra una mayor población extranjera, ya que acoge a 69.023 personas (49,5\% del total), de las cuales 28.965 están empadronados en Bilbao (8,2 \%). A su vez, Álava reúne a 28.010, que representan el 8,8 \% de la población. Por último, en Guipúzcoa residen 42.196, un 6 \% del total optando un 5,7 \% por vivir en Donostia-San Sebastián. Si hablamos de su procedencia, según datos del Observatorio Vasco de Inmigración (Ikuspegi) publicados en octubre de 2010, en Vizcaya el colectivo más numeroso es el latinoamericano (44\%), mientras que en Álava predominan los de origen africano y magrebí $(27,2 \%)$, y en Guipúzcoa los europeos (38,9\%). En cuanto a sus nacionalidades, destacan Rumania con 15.290 personas ( $11 \%$ del total), seguida de Marruecos con 14.386 (10,3\%), Colombia con 12.794 (9,2\%), Bolivia con 12.062 (8,7\%) y Portugal con 9.365 (6,7\%) (Ikuspegi, 08/ 2010).

Según el informe del Observatorio para la Diversidad (Mugak) su perfil responde a hombres (49,4\%) y mujeres (50,6\%) por igual, con edades comprendidas entre los 20 y 55 años y por lo tanto en edad para trabajar. El informe también revela que dos de cada tres mujeres inmigrantes residentes en Euskadi trabajan en el servicio doméstico. Asimismo, el 75\% de los empadronados en la comunidad está regularizado y unos 40.000 están afiliados a algún régimen de la Seguridad Social (Mugak, 9/06/2010). En lo que respecta a su actividad laboral la crisis afecta más a los hombres. El 50,3\% se encuentra sin empleo frente al 49,7 \% de las mujeres (INE:2 trimestre 2010). Entre los motivos que llevan a esta situación destaca que las mujeres trabajan principalmente en el cuidado de ancianos, niños y servicio doméstico. 


\section{Situación de los medios para inmigrantes latinos}

Durante los últimos años han surgido numerosos medios de comunicación tanto impresos como audiovisuales destinados a la población inmigrante. Algo lógico si se tiene en cuenta que en España en la actualidad suponen el 12,2 \% de la población. No obstante el colectivo más numeroso lo constituyen los extranjeros de origen latino. Con el fin de satisfacer las demandas de este amplio colectivo proliferan radios, televisiones, periódicos y revistas. Unos medios cuyo éxito viene avalado por las elevadas tiradas alcanzadas cada mes por periódicos con cobertura casi nacional como Latino (90.878 ejemplares), Si se puede (105.560 ejemplares), Noi În Spania (Nosotros en España) (18.811 ejemplares); además de Mundo hispano (9.072 ejemplares), Ocio latino (30.073 ejemplares), Raíz (699.88 ejemplares), Revista pueblo nuevo (21.335 ejemplares), y Toumai (50.001 ejemplares). Con una periodicidad quincenal destaca Baleares sin fronteras (34.201 ejemplares) (PGD: 2010) También en Madrid empieza a publicarse el primer diario para inmigrantes El nuevo Ciudadano (2007), pero deja de hacerlo en noviembre. Por otra parte, en el ámbito deportivo hay que destacar la revista mensual Pasión Deportiva3 (2007) (Santos, 2008: 607).

Además, existen numerosas emisoras de frecuencia modulada con cobertura nacional especializadas en temas latinos como Radio Gladis Palmera que inicia su andadura en Barcelona en 1999 con una programación centrada en música y boletines horarios con noticias del otro lado del Atlántico. En 2009 abre puntos de emisión en Madrid (103.2 FM) y Valencia (104.7 FM), aunque finalmente desde febrero de 2010 sólo se puede acceder a ella vía web. A esta iniciativa le siguen Radio Tentación, Zona Latina, Fiesta FM, Radio Libertad, Tropical FM, etc.. Siguiendo la misma tendencia, aunque de manera más escasa, surgen algunas televisiones como por ejemplo Latino Televisión.

Si nos centramos en la CAPV, los inmigrantes frecuentemente son protagonistas en los medios de comunicación, como en el magazine Pásalo (ETB); La Tertulia con Julio Flor (Canal Bizkaia); Bilbao Capital (TeleBilbao), que además organiza cada año un concurso de bailes caribeños; Encuentro Latino que se emitía en Localia Tv y el programa Nuevo Euskadi (Euskadi Irratia). Entre las emisoras en FM destacan Radio Tropical (2001) con presencia en Bilbao (102.9), Vitoria-Gasteiz (89.9) y Donostia-San Sebastián (101.6), y Fiesta FM (2009) que forman parte del Grupo de Comunicación Nervión. En el año 2006 la cadena nacional Local FM (90.3) llega a Bilbao y posteriormente a Vitoria-Gasteiz (88.8) y Donostia-San Sebastián (95.2). También hay que mencionar a Candela Radio (91.4 FM) que emite desde Bilbao. Finalmente, como resultado de la colaboración entre la asociación Colombia-Euskadi y la Diputación de Álava se pone en marcha en 2009 radio Prisma (90.3 FM (Elcorreodigital.es 14/02/09).

Estas emisoras coinciden en ofrecer una programación de escasa elaboración compuesta por música de ritmos caribeños como salsa, merengue, bachata, vallenato, pop latino, etc., junto con informativos breves. Otras comunidades, como la magrebí o la china, acceden a canales en su idioma que emiten desde Londres, EE UU o Hong Kong a través de la parabólica, aunque los más jóvenes de estos colectivos lo hacen, cada vez más, a través de las páginas web y los medios locales (Correodigital.es 2006/12/31). 


\section{El perfil de las publicaciones analizadas}

Entre los periódicos gratuitos publicados en la CAPV se encuentra un primer grupo promovido por los propios inmigrantes como instrumento para fomentar la integración. Su distribución en lugares frecuentados por este sector de población hace que sus mensajes lleguen a los destinatarios de manera efectiva. La primera iniciativa tiene lugar en Bilbao con Etorkinen ahotsa (2003). Su finalidad era dar una imagen más real de su situación y fomentar la integración. Cada mes repartía 18.000 ejemplares en asociaciones, universidades, escuelas públicas, centros de educación, iglesias y empresas situadas en el País Vasco y Navarra. En el 2005 se asociaron con Voces del Mundo y lanzaron la versión digital de Etorkinen AhotsaVoces del Mundo. Esta nueva apuesta presentaba como novedad más significativa la información en siete idiomas con el fin de ampliar su proyección al territorio nacional y a la comunidad internacional. No obstante, sus expectativas no se cumplieron y en el 2006 dejan la actividad. Sus contenidos se agrupaban en temas de actualidad, agenda, sociedad y entretenimiento.

Otro periódico, El Boga (2005) comienza su andadura en Vitoria, también impulsado por un grupo de inmigrantes. Su objetivo se centra en ser un medio de integración para los inmigrantes, pero a la vez también quiere servir para facilitar la opinión. Con una periodicidad mensual y una tirada de 7.000 ejemplares, en un primer momento se distribuía en mano y en depósitos en lugares frecuentados por este colectivo de Álava, Vizcaya, alto Guipúzcoa, Rioja y Aranda del Duero. Carece de subvención pública, de modo que se financia mediante publicidad. Este periódico como consecuencia de la crisis económica disminuyen sus ingresos y con el fin de continuar en el mercado reduce su tirada a 5.000 ejemplares, que reparte solo en Vitoria y alrededores. Además su periodicidad queda supeditada a la cobertura de los gastos que ocasiona la publicación y no cuenta con página web.

En Vizcaya surge Nuevo Euskadi (2007), por iniciativa de tres periodistas inmigrantes. Su tirada alcanzaba los 10.000 ejemplares mensuales, que se distribuían en 135 puntos de Bilbao y su Área mediante depósitos en locutorios, consulados, bibliotecas y zonas de reunión. En 2009 acusa un descenso en la venta de espacios publicitarios y empiezan a salir cada dos meses con una tirada a 2.000. Ante la precaria situación comienzan los trámites para constituirse en asociación. En sus 16 páginas mezclan información de actualidad, con contenidos de utilidad como guías prácticas, explicando los pasos a seguir a la hora de resolver algunas situaciones. En diciembre de 2009 no puede hacer frente a la crisis y deja de salir, tampoco disponía de página web.

Un segundo grupo de publicaciones gratuitas lo constituyen periódicos que integran grupos de comunicación con importantes tiradas y cobertura. Tal es el caso de Ediciones Toumai que pone en el mercado cada mes la revista Toumai (2003) con ediciones en Madrid, Barcelona y Nacional. En octubre del 2006 amplia su cobertura a Valencia, Andalucía, Murcia, Castilla-La Mancha, Galicia, Navarra, Rioja y Aragón. Finalmente, desde el 2008 Toumai cuenta con un suplemento Norte para País Vasco y Navarra con 10.000 ejemplares. Sus objetivos se centran en el colectivo de inmigrantes residentes en las 
distintas comunidades. Incluye secciones locales, de vida, deporte, música y entrevistas. Cabe destacar que en la publicación general, aunque escribe en castellano, introduce páginas traducidas al árabe, rumano y urdu (Pakistán).

De igual modo, editado por Copernal Publishing S.L., en septiembre del 2005 surge Raíz con una tirada de 150.300 ejemplares. Cada mes se reparte en formato revista en 2.500 lugares relacionados con los inmigrantes de ciudades como Madrid, Barcelona, Alicante, Sevilla, Santander, Valencia, Castellón, Murcia y Almería. A últimos del 2006 saca Raíz Norte para el País Vasco. No obstante, sus objetivos no se alcanzaron y en noviembre del 2007 se reestructura la publicación y dejan de salir las ediciones de Sevilla, Santander, Almería y País Vasco. Pero a pesar de esto, emplea su página web para introducir noticias de Andalucía, Asturias, Aragón, Baleares, Cataluña, Castilla y León, Euskadi, Madrid, Valencia y Extranjería. Además, esta cabecera se fragmenta en Raíz marroquí, Rumana, Ecuatoriana y Colombiana. Aborda en sus páginas actualidad, entretenimiento, contenidos de utilidad -como asesoramiento en temas familiares o legalización-, asociaciones, música, literatura, y servicio público de Ecuador y España. De esta manera cubre las necesidades informativas de africanos, marroquíes, ucranianos, rumanos, búlgaros, chinos y el colectivo hispano parlante de bolivianos, dominicanos, paraguayos, peruanos, ecuatorianos, colombianos y argentinos. El grupo editorial Copernal Publishing cuenta en el mercado con catorce revistas para colectivos de inmigrantes, que reparte en locutorios, tiendas de alimentación, asociaciones y consulados destacando entre otros: Revista Hoy Fin de Semana, Revista Hoy Viajes, Revista Hoy Motor, Revista Hoy Cine y Videojuegos. Estas publicaciones actualmente pretenden llegar no solo a los inmigrantes, sino al público en general con el fin de fomentar la integración en sentido bidireccional.

Tabla I. Periódicos gratuitos para inmigrantes en la CAPV

\begin{tabular}{|l|l|l|}
\hline & Año Origen & Cobertura 2009/10 \\
\hline El Boga & 2003 & Vitoria y alrededores \\
\hline Nuevo Euskadi & $2007-2009$ & Bilbao y Área Metropolitana \\
\hline Toumai & 2008 & Euskadi y Navarra \\
\hline
\end{tabular}

Fuente: Elaboración propia

\section{Análisis de los contenidos}

Los periódicos analizados en su conjunto abordan de manera similar los aspectos relacionados con la multiculturalidad, el fomento de la integración y el servicio. Destacan los contenidos específicos en temas de ámbito local, algo que se convierte en un valor añadido, como pueden ser temas sanitarios, jurídicos, administrativos, permisos de residencia y trabajo. Es decir, algo que según Diezhandino proporciona un efecto útil con respuestas y pautas concretas les ayudan a resolver problemas al lector en algún momento (1994:74). La idea de servicio no es reciente, pues ya en 1938 MacDougall consi-

$64 \mid n^{\circ} 14$ | doxa.comunicación 
deraba que un periódico, además de ofrecer información y entretenimiento en sus páginas, debía ofrecer consejos. Es decir, algo que según Metzler "da respuesta a muchas cuestiones que preocupan a la gente día a día” (Metzler, 1986: 219). Además incluyen información de sus países de procedencia. Están escritos en un lenguaje sencillo, de fácil comprensión, dando un carácter positivo y optimista, como por ejemplo cuando presentan formas de vida de compatriotas. Para reflejar de manera más fiel este sentimiento sus redacciones están integradas por periodistas españoles e inmigrantes. Del análisis de sus contenidos se observa:

1) En la sección de actualidad abordan asuntos cercanos, que les atañen de manera directa. Se aprecia por un lado el ámbito nacional en temas referentes a nacionalización, regularización, legislación como se refleja en Nuevo Euskadi: Discriminación: el sello institucional. Trabajadores de locutorios critican la nueva normativa. España endurece la política migratoria. Top manta: la unión hace la fuerza. Además acercan la información local en cuanto política, sociedad y economía, actividades y eventos en secciones como En el barrio, o Redada en Zorrozaurre que incluye Nuevo Euskadi. Estos contenidos siguen una evolución muy dispar, mientras en El Boga se produce un importante retroceso, en Toumai Norte se incrementa (Tabla 2). La información de sus países de origen resulta algo imprescindible para los inmigrantes, que en su mayoría deja familia allí. Incluyen noticias como El Salvador será..., Ecuatorianos: viajar para votar. También en Toumai Norte, La realidad tras el burka, El pueblo de Sarayaku. África imprescindible.

2) Los contenidos de utilidad son una constante. Contienen información que necesitan a la hora de solucionar sus problemas en materia de vivienda, educación y sanidad principalmente. También consejos para resolver una situación concreta, como puede ser la manera de afrontar entrevistas de trabajo, sugerencias sobre su condición legal, las dificultades para regularizar su situación, los pasos para conseguir la nacionalización y los reagrupamientos familiares. Aunque ahora ya no se habla tanto de papeles y regularización, porque en la mayoría de los casos están legalizados y aspiran a la nacionalidad. Presentan información sobre problemas que se plantean en esta nueva etapa en la que están integrados, como en Nueva Euskadi con Asesoría: preguntas y respuestas. En materia económica aportan la opinión de expertos así como sugerencias, que ayudan a elegir un crédito o la hipoteca más adecuada, o la negociación de la hipoteca. Proporcionan consejos como por ejemplo para acertar en la elección de la tarjeta prepago más conveniente, tal es el caso de Toumai Norte con el especial Tarjetas prepago: las líneas prepago en cuenta regresiva. La utilidad también se manifiesta en las recetas de cocina, como en Nuevo Euskadi con el rincón gastronómico que incluye la manera de elaborar platos de cocina española y latinoamericana, igual que en El Boga en miscelánea con recetas como por ejemplo Ensalada completa de verano. El servicio y la proximidad continúa presente con una completa relación de teléfonos y direcciones de consulados, Caritas diocesana, SOS racismo, oficina de extranjería, trabajo y otras guías de interés para inmigrantes, además de actividades culturales, convocatorias de becas y cursos. Las guías introducen explicaciones detalladas encaminadas a resolver una situación 
determinada. Toumai Norte con direcciones y web claves entre las que destacan Coordinadora Harresiak, Empleo y formación en Euskadi, Comisiones españolas de ayuda al refugiado, Servicio de integración. Se trata en definitiva de dar respuesta a qué hacer ante diferentes trámites administrativos, de mercado laboral, consejos encaminados a mejorar el bienestar, explicaciones y recomendaciones (Tabla: 2).

3) En el tiempo de ocio y entretenimiento ofrecen amplia información en cuanto se refiere a espectáculos, salud, belleza, familia, gastronomía y consultorios, entre otros temas. También resultan de interés los recorridos por las distintas zonas, como en Nuevo Euskadi con la sección Conocer Euskadi. Opción compartida en Toumai Norte con Festival de gentes del mundo para ocio, Excursiones culturales desde Vitoria, Tren turístico o Fiesta de la Capoeira. Además de propuestas culturales como Concurso de cortos con móvil y Teatro. Presentan el cine con comentarios sobre las películas favoritas, junto con música y las producciones discográficas más importantes de artistas latinoamericanos. No obstante, estos contenidos muestran un retroceso como consecuencia del incremento de su periodicidad.

4) En sociedad y cultura aborda formas de vida en ambas culturas y además incluye entrevistas a personajes de interés. Del mismo modo reflejan sus costumbres con el fin de promover los valores autóctonos y mantener los lazos de unión. Un ejemplo lo tenemos en El Boga, donde cubren las celebraciones religiosas de cada nacionalidad, así como las festividades relacionadas con vírgenes de distintos países latinoamericanos y también tradiciones como Chamanes: tradición o superchería. El chamanismo amazónico es tema de actualidad, estudio y curiosidad. Una sección que está presente en todos los periódicos con una tendencia ascendente.

5) El deporte adquiere especial relevancia en los periódicos. Destaca mayoritariamente el fútbol, como ocurre en Toumai Norte, que ofrece amplia información del Mundialito de fútbol sin fronteras y de las otras ligas de inmigrantes. Además introduce noticias sobre los clubes vascos de fútbol, rugby o fútbol sala. De esta manera las ligas de fútbol que se juegan en España y en Latinoamérica están completas. 
Tabla II. Noticias por sección

\begin{tabular}{|c|c|c|c|c|c|c|}
\hline & \multicolumn{2}{|c|}{ El Boga } & \multicolumn{2}{|c|}{ Nuevo Euskadi } & \multicolumn{2}{|c|}{ Toumai Norte } \\
\hline Sección & 2009 & 2010 & 2009 & 2010 & 2009 & 2010 \\
\hline Agenda & 5,50 & 8,00 & 0,00 & - & 5,00 & 3,50 \\
\hline Actualidad & 11,00 & 4,00 & 15,50 & - & 12,00 & 19,50 \\
\hline Deportes & 10,00 & 16,5 & 3,00 & - & 9,00 & 10,00 \\
\hline Opinión & 5,50 & 4,00 & 7,00 & - & 4,00 & 4,00 \\
\hline C. Utilidad & 12,00 & 14,00 & 10,00 & - & 12,00 & 10,00 \\
\hline Noticias allá & 15,00 & 16,50 & 12,00 & - & 8,00 & 10,00 \\
\hline $\begin{array}{l}\text { Sociedad/ } \\
\text { Cultural }\end{array}$ & 30,00 & 33,00 & 29,50 & - & 36,00 & 35,00 \\
\hline Entretenimiento & 11,00 & 4,00 & 19,50 & - & 14,00 & 8,00 \\
\hline Clasificados & 0,00 & 0,00 & 3,50 & - & 0,00 & 0,00 \\
\hline Otros & 0,00 & 0,00 & 0,00 & - & 0,00 & 0,00 \\
\hline
\end{tabular}

Fuente: Elaboración propia

\section{Su publicidad}

En el negocio de la publicidad se han producido cambios relevantes en algunos sectores. Entre los más afectados resulta ser el del automóvil, que registra un descenso del 86 \% en el último año, principalmente por las fuertes restricciones de créditos impuestas por las entidades financieras. Mientras, los bancos han pasado de ofrecer hipotecas a renegociarlas para no perder la casa, y también destacan los seguros de repatriación. Las medidas adoptadas por los editores para reducir costes hace que estos soportes pierdan interés para las empresas de publicidad. No se puede olvidar que sus destinatarios son las principales víctimas de la situación económica. Según los datos de población publicados por el Instituto Nacional de Estadística (INE), la tasa de desempleo de trabajadores inmigrantes en octubre de 2010 alcanzó la cifra de 997.658 de personas, lo que supone que casi uno de cada cinco inmigrantes está en paro. Su publicidad se incide en los siguientes sectores:

1) La banca que encamina sus objetivos a captar población inmigrante. En un primer momento la publicidad se centraba en conseguir hipotecas para la adquisición de viviendas, donde las propias inmobiliarias efectuaban una labor de mediación con las entidades bancarias, que a su vez ofertaban créditos y cuentas en condiciones especiales. Entre las hipotecas de los bancos el 15 \% corresponde a inmuebles adquiridos por los inmigrantes, y hoy día en España cerca de 500.000 tienen problemas con sus pagos. Sólo en el 2008 los impagos se incrementaron 
hasta un 310\% y alcanzaron 53.696 ejecuciones, según estadísticas de la Asociación Nacional de Establecimientos Financieros de Crédito (Asnef-Equifax, 2009). Esta tendencia continúa en 2010 llegando en junio a la cifra de 27.000 demandas hipotecarias ejecutadas por no poder hacer frente a sus pagos mensuales. Algunas familias, además de la hipoteca, tienen dos préstamos personales y una tarjeta de crédito. En esta situación los bancos pasan a buscar soluciones para aplazar los pagos de sus hipotecas con el fin de no perder las viviendas. Asimismo ofrecen servicios específicos como envíos de dinero a sus países, tarjetas telefónicas, seguros de repatriación y microcréditos (Tabla 3).

2) Las empresas de telecomunicaciones lanzan ofertas con descuentos en llamadas internacionales y de telefonía móvil con el objetivo de captar clientes en este sector de población. Según revela el estudio Nielsen sobre Hábitos de Consumo de Telecomunicaciones de Inmigrantes Latinoamericanos en España, tienen móvil el 98 \% de ellos, aunque sólo el 2 \% lo utiliza en llamadas de larga distancia como primera opción y un 6 \% como segunda. De este modo, los locutorios son para el $55 \%$ el lugar preferido para realizar llamadas a sus países de origen con un gasto de unos 10 euros mensuales (Nielsen: 2010). Otra consecuencia de la crisis se manifiesta en la rebaja de los gastos de teléfono. Necesitan un móvil para buscar empleo y relacionarse con amigos. Los inmigrantes latinos que viven en España han reducido en un 17\% los gastos en telefonía móvil situándose en 34,4 euros mensuales en tarjetas prepago. Además el $27 \%$ dispone de ordenador aunque sólo el $15 \%$ cuenta con conexión a Internet, en el que gasta 27,32 euros (Nielsen: 2010).

3) Los envíos de remesas a través de agentes es una publicidad que se incluye en los periódicos. El $90 \%$ de los inmigrantes mandan dinero todos los meses a sus países de origen. Según el Banco de España, solo en el segundo trimestre del 2010 las remesas expedidas por los inmigrantes residentes en España alcanzaron un valor de 1.757 millones de euros, frente a los 1.209 millones registrados en el último trimestre de 2009, lo que supone un incremento de un 16,3\% en tasa interanual (Cincodias.com 15/10/2010). El $85 \%$ de las transferencias las realizan a través de agentes remesadores, que intentan mantener el mercado y les ofrecen una amplia gama de servicios como envíos de documentos, paquetes, fotocopias, internet, alquiler de PC, envío y recepción de fax (véase Remesas.org, 2010).

4) Completan la publicidad con cursos de formación encaminados a elevar el nivel cultural para mejorar su situación laboral. Predominan los estudios de técnicos en farmacia, parafarmacia, dietética, nutrición, educación infantil, nuevas tecnologías y sectores relacionados con la energía solar entre otros (Tabla: 3).

En los periódicos analizados existe una mezcla de publicidad de marcas que corresponden a entidades bancarias como BBK, La Caixa, Caja Vital y telefonía como Moviestar, Vodafone principalmente, junto con otra de establecimientos de su entorno. Es el caso de Toumai Norte (7,8 \%) donde el ámbito local está presente con establecimientos de alimentación que marcan la diferencia los productos de sus países. De igual modo sucede con los restaurantes que, de manera reiterada, re- 
saltan la música latina y destacan como especialidad las comidas típicas. También en Nuevo Euskadi aparecen los servicios de asesorías con servicios integrales y en El Boga las academias de bailes latinoamericanos.

Tabla III. La publicidad por sectores

\begin{tabular}{|l|l|l|l|l|l|l|}
\hline & \multicolumn{2}{|c|}{ El Boga } & \multicolumn{3}{c|}{ Nuevo Euskadi } & \multicolumn{2}{c|}{ Toumai Norte } \\
\hline Sectores & 2009 & 2010 & 2009 & 2010 & 2009 & 2010 \\
\hline Institucional & 20,00 & 9,00 & 4,00 & - & 0,00 & 12,50 \\
\hline Ocio/viajes & 4,00 & 9,00 & 0,00 & - & 4,00 & 0,00 \\
\hline Bancos & 16,00 & 20,00 & 44,00 & - & 26,00 & 37,50 \\
\hline $\begin{array}{l}\text { Consultorías/ } \\
\text { Asesorías }\end{array}$ & 8,00 & 3,00 & 7,50 & - & 14,00 & 0,00 \\
\hline Envíos remesas & 6,00 & 6,50 & 7,50 & - & 18,00 & 0,00 \\
\hline Telefonía & 12,00 & 6.50 & 0,00 & - & 6,00 & 25,00 \\
\hline Restaurantes & 12,00 & 6,50 & 0,00 & - & 0,00 & 0,00 \\
\hline Alimentación & 12,00 & 6,50 & 0,00 & - & 6,00 & 0,00 \\
\hline Enseñanza & 4,00 & 10,00 & 0,00 & - & 26,00 & 12,50 \\
\hline P. Propia & 0,00 & 18,00 & 37,00 & - & 0,00 & 0,00 \\
\hline Importación & 2,00 & 2,00 & 0,00 & - & 0,00 & 0,00 \\
\hline Otros & 4,00 & 3,00 & 0,00 & - & 0,00 & 12,50 \\
\hline
\end{tabular}

Fuente: Elaboración propia

\section{Una difícil supervivencia}

Ocio Latino (1995) fue la primera revista destinada a la población inmigrante en España. A partir de este momento han sido muy numerosos los medios surgidos con la finalidad de responder a las exigencias de comunicación de este colectivo que, según el Ministerio de Trabajo e Inmigración, en febrero de 2010 alcanzaba los 4,8 millones con tarjeta en vigor, de los cuales el 30,4\% son ciudadanos latinoamericanos. De igual modo, que sus contenidos la publicidad insertada en sus páginas presenta mensajes para colectivos con patrones de consumo propios. Necesitan enviar remesas, la banca y las telecomunicaciones, pero más tarde se incorporan otros sectores como seguros, agencias de viajes, moda, inmobiliarias, clínicas dentales y consultorías. En definitiva, la atención a la diversidad cultural es clave para el éxito comercial de las empresas, que empiezan a integrar a los inmigrantes en su proceso de segmentación de mercados.

La prensa gratuita, después de unos años de gran expansión, acusa la crisis económica y se ven obligados a practicar recortes de plantilla, cierres de publicaciones y delegaciones con el fin de disminuir costes de producción. A pesar de que 
todos estos medios dependen de la publicidad, los más pequeños resultan más vulnerables a la situación que atraviesan sus empresas ya que sufren una importante reducción de ingresos por una publicidad que en su mayoría es de ámbito local. Entre las medidas tomadas destacan:

1) Una disminución en el número de páginas editadas. Es el caso de la revista Toumai, que de 48 pasa a imprimir entre 8 y 24. Una opción que también toman los editores de los diarios gratuitos de información general: Qué (de 24 a 16 páginas), 20 Minutos (28 a 16) y $A D N$ (32 a 20), aunque es preciso mencionar que varían en función de la publicidad y de los contenidos. Los editores también optan por reducir las tiradas. Así El Boga pasa de 7.000 ejemplares a 5.000, y Nuevo Euskadi desciende de 10.000 a 2.000 ejemplares, mientras la revista Toumai se mantiene en 10.000 ejemplares (Tabla: 4).

Tabla IV. Evolución de tirada y páginas en periódicos gratuitos para inmigrantes CAPV

\begin{tabular}{|l|l|l|l|l|}
\hline & Año Origen & Tirada origen & Tirada 2009/10 & Páginas \\
\hline El Boga & 2003 & 7.000 & 5.000 & 16 \\
\hline Nuevo Euskadi & $2007-2009$ & 10.000 & 2.000 & 16 \\
\hline Toumai & 2008 & 10.000 & 10.000 & $8-24$ \\
\hline
\end{tabular}

Fuente: Elaboración propia

2) Además se producen reajustes en su ámbito de cobertura. Por ejemplo, El Boga que comenzó repartiéndose en Vizcaya y zonas limítrofes de Rioja y Burgos ha quedado reducido a la capital alavesa. El periódico Toumai, que se distribuía en Madrid, Barcelona, Alicante, Sevilla, Santander, Valencia, Castellón, Murcia, Almería, País Vasco y Navarra queda restringido a Madrid, Barcelona y edición Norte para Navarra y Euskadi. Asimismo, concentra los puntos de reparto y depósitos fijos en lugares frecuentados por inmigrantes.

3) Los cambios en su periodicidad es otra de las medidas tomadas por los editores. Los periódicos analizados coincidían en una periodicidad mensual, pero solo la revista Toumai logra mantenerla. En 2009 El Boga y Nuevo Euskadi acusan una disminución en la venta de espacios publicitarios y empiezan a salir cada dos meses y más tarde se condiciona a la cobertura de los gastos de edición, algo que Nuevo Euskadi no consigue y cierra (Tabla: 5). 
Tabla V. Periodicidad periódicos gratuitos para inmigrantes CAPV

\begin{tabular}{|l|l|l|}
\hline & Origen & $2009 / 2010$ \\
\hline El Boga & Mensual & Indeterminada \\
\hline Nuevo Euskadi & Mensual & 2 meses/cierre \\
\hline Toumai & Mensual & Mensual \\
\hline
\end{tabular}

Fuente: Elaboración propia

La reducción de páginas y cobertura, unido al descenso de sus tiradas e incrementos en su periodicidad, tiene como consecuencia cambios en los contenidos, sobre todo en las cabeceras más pequeñas. Resultan las más afectadas las secciones de actualidad y entretenimiento pasan a ser casi testimoniales dado que no superan el 4 \%. En contraposición se incrementan las secciones de sociedad y cultura.

Estos ajustes suponen una pérdida de interés por parte de los anunciantes que dejan de comprar espacio publicitario y con ello la reducción de los ingresos (Raíz 08/09/2009). Así El Boga y Nuevo Euskadi resultan más afectados dado que se editan de manera independiente y se financian con publicidad básicamente de pequeños establecimientos como peluquerías, restaurantes y establecimientos de alimentación de su ámbito de cobertura. Entre los años 2009 y 2010 se observa una importante merma de publicidad en ambos periódicos, que llenan con inserciones de publicidad propia, que el caso de Nuevo Euskadi alcanza el 68 \%. En cuanto a sectores en El Boga disminuyen de manera significativa los establecimientos de ámbito local (25\% a 16,5 \%), mientras que en Nuevo Euskadi descienden marcas (39,5\% a 14 \%) y la Institucional (30\% a 4 \%). Este periódico es el que más ha notado la crisis y su falta de financiación lo hace inviable y deja de salir en diciembre de 2009.

En cambio Toumai Norte que cuenta con el respaldo de un grupo de comunicación, logra mantener la publicidad de grandes marcas y las de ámbito local. Por otra parte, su reparto es selectivo: locutorios, tiendas de alimentación, asociaciones, consulados y en general sitios frecuentados por los inmigrantes. Esto garantiza que el producto llegue al consumidor, de manera más eficaz. A pesar de las circunstancias, sus contenidos no se han visto alterados y continúan ofreciendo información sobre temas que les atañen de manera directa con pautas y consejos de utilidad en temas como empleo, formación, asesoramiento jurídico y agenda, trámites administrativos de residencia y trabajo e información sobre el mercado laboral. En cuanto se refiere a la superficie publicitaria Toumai Norte logra mantenerla en el $25 \%$ sin acusar la diferencia en el número de páginas que edita. 
Tabla VI. Superficie publicitaria según sectores

\begin{tabular}{|l|l|l|l|l|l|l|}
\hline & \multicolumn{2}{|c|}{ Boga } & \multicolumn{2}{c|}{ Nuevo Euskadi } & \multicolumn{2}{c|}{ Toumai Norte } \\
\hline & 2009 & 2010 & 2009 (Enero) & $\begin{array}{l}2009 \\
\text { (Diciembre) }\end{array}$ & 2009 & 2010 \\
\hline Local & 25,00 & 16,50 & 7,50 & 14,00 & 0,00 & 8,00 \\
\hline Marcas & 40,00 & 67,00 & 39,50 & 14,00 & 80,00 & 64,00 \\
\hline Institucional & 30,00 & 0,00 & 30,00 & 4,00 & 18,00 & 20,00 \\
\hline P. Propia & 5,00 & 16,50 & 23,00 & 68,00 & 2,00 & 8,00 \\
\hline
\end{tabular}

Fuente: Elaboración propia

\section{Conclusiones}

En la CAPV los periódicos destinados a inmigrantes tienen como objetivo fundamental dar una imagen real de su situación y fomentar la integración y la multiculturalidad. Se editan los periódicos locales El Boga y Nuevo Eus$l k a d i$. Unas pequeñas publicaciones que afectadas por la crisis intentan subsistir adoptando medidas como la reducción de tirada, periodicidad y cobertura. No obstante, Nuevo Euslkadi se vio obligado a cerrar. También en la autonomía se distribuye la revista Toumai Norte que forma parte de una empresa con cobertura nacional y soporta mejor los efectos de la crisis.

- $\quad$ En cuanto a sus contenidos los periódicos gratuitos analizados coinciden en destacar la actualidad de su entorno mas cercano en temas que les afectan de manera directa como legislación, trabajo o sanidad. Ofrecen información de utilidad y servicio incluyendo sugerencias, recomendaciones, guías y consejos para resolver una situación concreta, junto con datos de interés como teléfonos de urgencia y asociaciones entre otros. También adquiere especial relevancia la información de sus países de origen. Es decir, abundan los contenidos con una filosofía de servicio ayudando a fomentar los valores culturales, así como la integración.

Se constata una publicidad de marcas en sectores que dan respuesta a sus necesidades inmediatas. Predominan los bancos (BBK, Santander, Caja Vital) con información sobre prestaciones específicas para este colectivo en materia de seguros de repatriación, envíos de dinero y facilidades para negociar hipotecas. De igual modo, empresas de telefonía móvil (Movistar y Vodafone) presentan ofertas de contratos y líneas para hablar con sus países. Asimismo, los envíos de remesas ocupan una parte importante de la publicidad en los periódicos analizados. También existe una publicidad local centrada en el pequeño comercio como restaurantes, establecimientos de alimentación y academias.

72 | no 14 | doxa.comunicación 


\section{Referencias bibliográficas}

Correodigital.com 31/12/06: "El reino de la antena parabólica". Disponible en: http://www.elcorreodigital.com/vizcaya/ prensa/20061231/sociedad/pais-vasco-reino-antena_20061231.html. [Consultado el 08/10/09]

Correodigital.com 14/02/09: "La radio desde otro prisma". Disponible en: http://www.elcorreodigital.com/alava/ 20090214/cultura/radio-desde-otro-prisma-20090214.htm/. [Consultado el 22/10/09]

CincoDías.com (17/11/2010): “Las remesas de los inmigrantes suben un 4,9\%”. Disponible en: http:/ /www.cincodias.com/ articulo/empresas/remesas-inmigrantes-suben-49/20101010cdscdsemp_1/. [Consultado el 18/11/2010]

Diezhandino, M. P. (1994): Periodismo de servicio: Evolución y Perspectivas. Bilbao: UPV.

Diezhandino, M. P. et al. (2010): Periodismo digital en tiempos de crisis. Un caso de estudio: el tratamiento de la inmigración en los medios. Barcelona: Ariel.

Elpais.com 07/07/05: "Euskadi no es atractiva para la inmigración”. Disponible en: www.elpais.com/.../pais/vasco/Euskadi/atractiva/inmigracion/informe/.../Tes/. [Consultado el 22/10/10]

González, E. (2009): "La consolidación de las publicaciones para extranjeros en España”, Revista Latina de Comunicación Social, n. ${ }^{\circ}$ 64, pp. 708-724. Disponible en: http//www.revistalatinacs.org/09/art/856_UMA/ 57_91_maría_Eugenia_Gonzales_Cortes.html.

Informe Centro de Estudios y Documentación sobre Inmigración, Racismo y Xenofobia. Disponible en http://www.mugak.eu/gunea/

Informe Observatorio Vasco de Inmigración (Ikuspegi). Disponible en http://www.ikuspegi.org/es/

Nielsen (2010): “Ómnibus Inmigración. The Nielsen Company”. Disponible en: http://es.nielsen.com/trends/est_inmigrantes.shtml. [Consultado el 12/09/10]

Martins de Mendoca, L. (2008). "La presencia de los inmigrantes y del proceso de inmigración en la prensa gratuita barcelonesa: estudio exploratorio”, Ámbitos, n. 17, pp. 147-161.

Santos, T. (2008): “Periódicos gratuitos para inmigrantes. Noticias de acá y de allá”, Estudios sobre Mensaje Periodístico, n.ํำ 14 , pp. 605-616.

- (2008): El auge de la prensa gratuita en España. Bilbao: UPV/EHU. 